\title{
Positive organisation: The role of leader behaviour in work engagement and retention
}

\author{
Authors: \\ Fallen Mendes ${ }^{1}$ \\ Marius W. Stander ${ }^{1}$ \\ Affiliations: \\ ${ }^{1}$ Reasearch Program of \\ Behavioural Sciences, \\ North-West University, \\ Vaal Triangle Campus, \\ Vanderbijlpark, South Africa \\ Correspondence to: \\ Marius Stander \\ Email: \\ marius.stander@nwu.ac.za \\ Postal address: \\ PO Box 1174, Vanderbijlpark \\ 1900, South Africa \\ Dates: \\ Received: 19 Mar. 2010 \\ Accepted: 11 Oct. 2010 \\ Published: 06 May 2011 \\ How to cite this article: \\ Mendes, F., \& Stander, M.W. \\ (2011). Positive organisation \\ The role of leader behaviour \\ in work engagement and \\ retention. SA Journal of \\ Industrial Psychology/SA \\ Tydskrif vir Bedryfsielkunde, \\ 37(1), Art. \#900, 13 pages. \\ doi:10.4102/sajip.v37i1.900
}

(C) 2011. The Authors. Licensee: OpenJournals Publishing. This work is licensed under the Creative Commons Attribution License.
Orientation: The positive organisation creates a framework in which its elements can be investigated in relation to the retention of talent.

Research purpose: The aim of this study was to investigate if leader empowering behaviour can positively impact on role clarity, psychological empowerment and work engagement, with the final outcome being the retention of talent.

Motivation for the study: In the ever changing work environment organisations place great emphasis on their human capital. The positive organisation utilises specific elements to optimise human capital's potential. It is therefore important to identify the elements contributing to a positive organisation as well as the elements which lead to the retention of talent.

Research design, approach and method: A survey research design was used. A convenience sample $(n=179)$ was taken from a business unit in a chemical organisation. The Leader Empowering Behaviour Questionnaire, Measures of Role Clarity and Ambiguity Questionnaire, Measuring Empowerment Questionnaire, Utrecht Work Engagement Scale and the Intention to Leave Scale were administered.

Main findings: Leader empowering behaviour, role clarity and psychological empowerment predicted work engagement. Role clarity interacted with competence to affect employees' dedication and interacted with the development of employees to affect absorption. Work engagement predicted employees' intention to leave.

Practical/managerial implications: Organisations should foster the elements of a positive organisation if they want to retain their talent.

Contribution/value-add: The results of this research contribute to scientific knowledge about the effects of a positive organisation on retention.

\section{Introduction}

The current business environment has become unstable and is characterised by continuous change and renewal (Malone, 2004; Sellgren, Ekvall \& Tomson, 2007). Globalisation has increased the workforce's mobility and employees are now expecting more from their employers than they previously did (Burke \& Cooper, 2009). In order to be dominant in a global economy, organisations are forced to take an interest in more than mere profitability. These interests include the attraction, development and retention of talent (Boninelli \& Meyer, 2004). The focus on talent is forcing organisations to adapt their business model in order to empower and engage their employees (Bakker \& Demerouti, 2008).

Becoming a healthy organisation that is continuously learning is the most effective way in which to address the forces impacting on organisations today (Wilson, DeJoy, Vandenberg, Richardson \& McGrath, 2004). To be successful, organisations need to focus on both performance and health (Conley, 2007). Organisations need to consider two types of resources in order to be healthy: those that support performance and those that support health (Burke \& Cooper, 2009). According to Macky and Boxall (2008), employees' well-being plays a vital role in the organisation's success. A healthy organisation is highly competitive in the war for talent, because it is aware of the tendency towards the information age which results in a greater demand for quality leadership and talent retention so as to avoid high staff turnover (Burke \& Cooper, 2009).

According to Bakker and Schaufeli (2008), the modern organisation places great emphasis on the management of human capital. Positive psychology is a more modern and effective approach, as it focuses on human strengths (Luthans, 2002). A positive organisation focuses on the dynamics 
within the organisation that lead to the development of human strength, foster vitality and flourishing employees, make possible resilience and restoration and cultivate extraordinary individual and organisational performance (Cameron, Dutton \& Quinn, 2003). Positive organisational behaviour fosters engaged employees and this is the key to ensuring high performance and overall wellness for both the organisation and its employees, whilst increasing the commitment of employees, thereby lowering the risk of losing talent (McHugh, 2001).

The main outcome of a healthy, positive organisation is the retention of talent (Davenport \& Harris, 2007; Ulrich, Brockbank, Johnson, Sandholtz \& Younger, 2008). These organisations focus on their employees with as much passion and enthusiasm as they do on new processes and products (Bryan \& Joyce, 2007). Talent management and the effective management of employee turnover is a central issue that is managed in order to avoid negative implications, such as high economic costs and disrupted social and communicative structures (Bergiel, Nguyen, Clenney \& Taylor, 2009). An increase in profits, employees' happiness and productivity and customer satisfaction results from the retention of employees (Kaye \& Jordan-Evans, 2000). The ability of leaders to empower their employees will have an impact on the organisation's labour retention (Kreisman, 2002; Taplin \& Winterton, 2007).

According to Snyder and Lopez (2002), leaders within an organisation play a vital role in designing a healthy work environment that encourages the talent of the organisation to stay. Furthermore, leadership behaviours have a strong influence on employee and organisational outcomes (Chen \& Silverthorne, 2005), including work engagement and turnover intention. Engaged employees are aware of the organisational context and work with others to improve performance within their roles for the benefit of the organisation (Devi, 2009). When employees are engaged, they become less likely to leave the organisation. Baskin (2007) reports similar findings stating that an employee who is not engaged is more likely to leave the organisation.

Whilst it is expected that empowering behaviour by leaders will impact on psychological empowerment, work engagement and turnover intention, it is not clear what the effect of role clarity would be. There was no evidence in the literature exploring the possible mediating or moderating effects of role clarity on the relationships between leader empowering behaviour, psychological empowerment and turnover intention. The aim of this study was to investigate the relationship between leader empowering behaviour, role clarity, psychological empowerment and work engagement.

\section{Leader empowering behaviour, role clarity and psychological empowerment}

Konczak, Stelly and Trusty (2000) identified six dimensions of leader empowering behaviour, namely:

- the delegation of authority
- the leader's ability to emphasise accountability

- encouragement of self-directed decision-making

- the leader's ability to share information

- development of skills

- coaching to promote innovation.

A leader's ability to demonstrate these behaviours will influence how employees perceive the tasks presented to them by their leader (Wilson et al., 2004). According to Greco, Laschinger and Wong (2006), employees will be empowered if a leader enhances the meaningfulness of work, allows participation in decision-making, facilitates the accomplishment of tasks, communicates confidence in high performance and provides autonomy. A leader that utilises empowerment creates benefits for both the organisation and the employees, as empowerment improves the economic performance of an organisation and reduces role conflict and role ambiguity amongst employees (Greasley et al., 2008).

According to Mardanov, Heischmidt and Henson (2008), employee behaviour depends on the relationship between an employee and the leader, as experienced by the employee. Every employee within an organisation should have a specified set of roles and these allow the leaders of an organisation to hold the employee accountable for performance (Rizzo, House \& Lirtzman, 1970). Mukherjee and Malhotra (2006) found that when a leader offers clarity in terms of these roles, a positive relationship results. Leader empowering behaviours influence employees' perceived role clarity in a positive way (Hong, Nahm \& Doll, 2004; Nielsen, Randall, Yarker \& Brenner, 2008). Leaders who provide guidance in terms of the tasks presented to employees create less uncertainty (Hong et al., 2004). Nielsen et al. (2008) support this in their findings that a positive relationship exists between supervisory consideration and perceived role clarity. Klidas, Van den Berg and Wilderom (2006) found that employees who indicated disempowerment due to leadership behaviours were experiencing low role clarity.

Role clarity consists of two concepts, namely role conflict and role ambiguity (Rizzo et al., 1970), Role conflict occurs when two or more conflicting job requirements arise, so that complying with one would make doing the other more difficult (Rizzo et al., 1970; Teh, Ooi \& Yong, 2008). Role ambiguity refers to the lack of clarity and predictability of the outcomes of one's behaviour (Rizzo et al., 1970; Slatten, 2008). Employees who feel empowered report low levels of role conflict and ambiguity (therefore higher levels of role clarity) in their roles because they are able to control their own environment (Greasley et al., 2008).

Psychological empowerment is a motivational construct manifested in four cognitions (Spreitzer, 1995):

- meaning, which refers to the value of a work goal or purpose, judged in relation to one's own ideals or standards

- competence, which is an individual's belief in his or her capability to perform activities with skill

- self-determination, which indicates the individual's sense of choice in initiating and regulating action

- impact, which is the degree to which an individual can 
influence strategic, administrative or operating outcomes at work.

This motivational approach stresses psychological enabling as the main reason for an individual's feelings of empowerment (Conger \& Kanungo, 1988; Menon, 2001; Spreitzer, 1995). Organisations which empower employees through greater meaning, competence, self-determination and impact in their work experience positive outcomes (Thomas \& Velthouse, 1990). Employees who are empowered offer the benefit of responding more quickly to environmental changes and stakeholder demands in comparison with their disempowered counterparts (Carson \& King, 2005). According to Greasley et al. (2008), organisations with higher levels of empowerment have demonstrated improvements in various economic performance areas, global competition, the constantly changing business environment and the ability to deal with pressures to improve efficiency and performance. When employees experience empowerment they also demonstrate higher levels of engagement (Greco et al., 2006).

Psychological empowerment is directed by the six dimensions of leader empowering behaviour (Konczak et al., 2000). Leader empowering behaviour is correlated with greater feelings of empowerment (Greco et al., 2006). According to Avey, Hughes, Norman and Luthans (2008) leadership style and psychological empowerment are significantly related to feelings of empowerment. Sauer (2003) found that leader empowering behaviour is significantly correlated to the degree of psychological empowerment that employees experience. There are two aspects of empowerment: empowerment as behaviour of a supervisor who empowers his or her subordinates and the psychological state of a subordinate resulting from his or her supervisor's ability to empower (Avey et al., 2008).

For the empowerment of employees to be successful, it is necessary to investigate the role of the leader because he or she has a substantial impact on the employee's perception of empowerment. It is the leader's responsibility to assess the employee's perceived feelings of empowerment (Greasley et al., 2004). An empowered organisation is one in which a leader encourages employees by involving them in decisionmaking and assigning responsibility to them (Malone, 2004). When leaders are effective in using empowering behaviours, employees are aware of the expectations placed upon them (role clarity) and they feel confident (empowered) in achieving them; consequently employees experience higher levels of engagement (Greco et al., 2006).

\section{Work engagement and turnover intention}

Work engagement is defined as a positive, fulfilling, work-related state of mind that is characterised by vigour, dedication and absorption (Schaufeli, Salanova, GonzálezRomá \& Bakker, 2002). Role clarity has been found to play a role in work engagement (Harter, Schmidt \& Hayes, 2002; Russel, 2008; Saks, 2006; Steele \& Fullagar, 2009). When expectations are not clarified employees are not engaged, as is evident in the expression of negative emotions like boredom and resentment (Harter et al., 2002). Increasing clarity of expectations was found to increase positive emotions that led to engagement of employees (Russel, 2008). When roles are not clearly defined, the likelihood of an employee's intentions to leave that job will increase because of the lack of role engagement (Steele \& Fullagar, 2009). Employees who perceive their environments as predictable and consistent are more engaged in their work (Saks, 2006). According to Konrad (2006), the more transparent managers are in terms of the organisation's operations, the more engaged employees will be. Coffman (2002) endorses this, stating that the best way in which to engage a workforce is through offering employees clarity in terms of the desired expectations of their roles. This is confirmed in the findings of Prieto, Salanova, Martinez and Schaufeli (2008) that role stress are negatively related to work engagement, with role ambiguity or clarity being a strong predictor of dedication, a sub-construct of work engagement.

Intention to leave is the strength of an individual's viewpoint that he or she does not want to stay with his or her employer (Kahumuza \& Schlechter, 2008). Intention to leave refers to the ultimate cognitive stage in the decision-making process of an employee, where quitting and searching for alternative employment occurs actively (Park \& Kim, 2009). According to Park and Kim (2009), an employee's intentions to leave an organisation consist of both thoughts and statements, but these intentions can differ from the employee's actual behaviour. Intention to quit has been found to be a strong predictor of actual turnover and may be the most important antecedent of employee turnover (Kahumuza \& Schlechter, 2008; Park \& Kim, 2009).

An employee's intention to leave is a signal valid indicator of quitting (Weisberg, 1994). According to Grobler, Wärnich, Carrell, Elbert and Hatfield (2006), a high turnover in employees costs South Africa several millions of rands a year through decreased productivity, increased accidents and quality problems. Taplin and Winterton (2007) found that organisations with a low record of turnover encompassed leaders who perceived turnover as a costly expense and so took a pro-active approach in dealing with the problem. Turnover is an outcome that a positive, healthy organisation avoids because it is disruptive and consequently costly (Grobler et al., 2006).

Greco et al. (2008) found that nurses who experienced psychological empowerment were more engaged in their work. Empowered employees demonstrate the characteristics of an engaged employee (Avey et al., 2008; Dvir, Eden, Avolio \& Shamir, 2002; Greasley et al., 2008; Reynders, 2005). Avey et al. (2008) found that empowerment is sub-sequential to engagement. This is substantiated in the findings of Stander and Rothmann (2010) who found that psychological empowerment was a statistically significant predictor of employee engagement. Competence and meaning are two sub-scales that encompass psychological empowerment and have been found to lead to work engagement. When employees experience meaning in their work they experience engagement (Luthans \& Peterson, 2001; May \& Harter, 2004). Engaged employees view themselves as competent in dealing with their job demands; they have positive self- 
efficacy (Schaufeli et al., 2002). Reynders (2005) found in her study of employees in a government institution, that higher levels of psychological empowerment encompass increased levels of work engagement.

Work engagement is related to attitudes, intentions and behaviours of employees (Saks, 2006). Engagement can be utilised as a tool to reduce employees' intentions to leave the organisation (Baskin, 2007). According to Bhatnagar (2007), employee engagement is the most effective way in which to retain talent. Nurses' intention to leave was studied by Karlowicz and Ternus (2007) and it was found that the lack of engagement was one of the most important issues contributing to intention to quit. Simpson (2009) found very similar results in her research with nurses, where higher turnover cognitions correlated directly with low work engagement levels. According to Saks (2006), employees who are more engaged are more trusting of their employer and therefore report more positive attitudes and intentions towards the organisation. It was also found that job and organisation engagement predicted an employee's intention to quit (Saks, 2006).

Based on the review of the literature, the hypothesised conceptual model of this study is graphically depicted in Figure 1 below:

Based on the aforementioned discussion, the following hypotheses are formulated:

- Hypothesis 1: Leader empowering behaviour, role clarity and psychological empowerment predict work engagement within the business unit.

- Hypothesis 2: Role clarity moderates the relationship between leader empowering behaviour, psychological empowerment and work engagement within the business unit.

- Hypothesis 3: Work engagement predicts intention to leave within the business unit.

\section{Research design}

\section{Research approach}

The objectives set out for this research will be achieved through a survey design (Shaughnessy \& Zechmeister, 1997). Information regarding respondents' experience of leader empowering behaviour, role clarity, psychological empowerment, work engagement and intention to leave was obtained through the administration of surveys.

\section{Research method}

\section{Participants}

This business unit consisted of 240 employees holding various positions such as managers, specialists, supervisors and administrative staff. Of the total questionnaires distributed 179 (75\%) were returned. Table 1 illustrates the characteristics of these participants.

The study population consisted of $60.3 \%$ male participants, whilst $39.7 \%$ were female. Furthermore, the sample comprised African (52.5\%), White (42.5\%), Indian (1.7\%) and Coloured $(0.6 \%)$ participants, of whom $7.8 \%$ were managers, $14.5 \%$ were specialists and $76.5 \%$ were non-management personnel. The ages of the participants ranged from 24 years and younger $(16.8 \%)$ to 56 years and older $(3.9 \%)$, with a majority of participants $(47.5 \%)$ in the age group of $25-35$ years.

\section{Measuring instruments}

The Leader Empowering Behaviour Questionnaire (LEBQ) was developed by Konczak et al. (2000) and is aimed at providing leaders with feedback with regard to employees' behaviour that relates to employee empowerment. The original instrument consists of 17 items and is scored on a 7-point Likert scale ranging from 'strongly disagree' (1) to 'strongly agree' (7). A typical item is 'My manager gives me the authority I need to make decisions that improve work processes and procedures' (Konczak et al., 2000, p. 307) and a high score signifies high leadership empowering behaviour. Two items were added from Arnold, Arad, Rhoades and Drasgow (2000) with the aim of increasing the number of items that demonstrated the 'information sharing' dimension. These items are 'My manager explains his/her decisions and actions to my work group' and 'My manager explains company goals to my work group'. In previous research (Konczak et al., 2000) the interfactor correlations ranged from 0.40 to 0.88 whilst a Cronbach alpha coefficient of 0.95 for reliability was found (Dwyer, 2001). Maré (2007) found Cronbach alpha coefficients ranging from 0.57 to 0.78 in a large sample within a gold mining industry in South

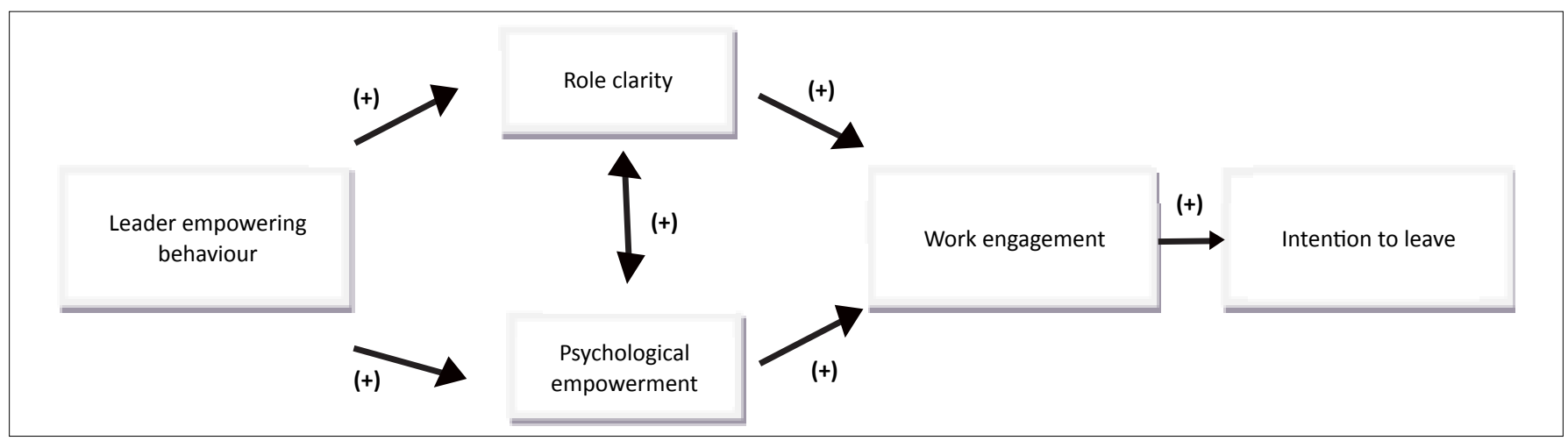

FIGURE 1: The hypothesised relationship between constructs. 
TABLE 1: Characteristics of the participants $(N=179)$.

\begin{tabular}{|c|c|c|c|}
\hline Item & Category & $f$ & $\%$ \\
\hline \multirow[t]{2}{*}{ Gender } & Male & 108 & 60.3 \\
\hline & Female & 71 & 39.7 \\
\hline \multirow[t]{6}{*}{ Race } & African & 94 & 52.5 \\
\hline & White & 76 & 42.5 \\
\hline & Indian & 3 & 1.7 \\
\hline & Coloured & 1 & 0.6 \\
\hline & Other & 1 & 0.6 \\
\hline & Missing values & 4 & 2.2 \\
\hline \multirow[t]{5}{*}{ Age } & 24 years and younger & 30 & 16.8 \\
\hline & $25-35$ years & 85 & 47.5 \\
\hline & $36-45$ years & 33 & 18.4 \\
\hline & $46-55$ years & 24 & 13.4 \\
\hline & 56 years and older & 7 & 3.9 \\
\hline \multirow[t]{6}{*}{ Qualification } & Up to Grade 11 & 3 & 1.7 \\
\hline & Grade 12 & 89 & 49.7 \\
\hline & Diploma & 63 & 35.2 \\
\hline & Degree & 13 & 7.3 \\
\hline & Degree + & 10 & 5.6 \\
\hline & Missing values & 1 & 0.6 \\
\hline \multirow[t]{5}{*}{ Service } & Less than 1 year & 32 & 17.9 \\
\hline & $2-5$ years & 53 & 29.6 \\
\hline & $6-10$ years & 31 & 17.3 \\
\hline & $11-20$ years & 33 & 18.4 \\
\hline & More than 20 years & 30 & 16.8 \\
\hline \multirow[t]{4}{*}{ Category } & Management & 14 & 7.8 \\
\hline & Specialist & 26 & 14.5 \\
\hline & Non-management & 137 & 76.5 \\
\hline & Missing values & 2 & 1.1 \\
\hline
\end{tabular}

f, frequency.

Africa. Maré (2007) found a one factor structure for LEBQ. Tjeku (2006) and Dwyer (2001) found that a 3-factor model was best in a study done within a steel manufacturing organisation. For the purpose of this study a simple principal components analysis was carried out on leader empowering behaviour items (as measured by the LEBQ). An analysis of the Eigenvalues $(>1.00)$ and scree plot indicated that three factors could be extracted, which explained $69.7 \%$ of the total variance. These were named Development, Accountability and Authority.

The Measures of Role Conflict and Ambiguity Questionnaire (MRCAQ) was developed by Rizzo et al. (1970) and is aimed at identifying role conflict and role ambiguity within complex organisations. The original instrument consists of 30 items, 15 of which deal with role ambiguity (even numbers) and 15 with role conflict (odd numbers). The measure is scored on a 7-point scale ranging from 'very false' (1) to 'very true' (7). Mukherjee and Malhotra (2006) found that the role ambiguity items of this measure should be renamed 'role clarity' and this is substantiated in other research (Beehr, Glazer, Fischer, Linton, \& Hansen, 2009; Bray \& Brawley, 2002) and therefore, for this study these items were utilised because role clarity is of interest. A typical item is 'explanation is clear of what has to be done' (Rizzo et al., 1970, p. 156) and a high score indicates high role clarity (or low role ambiguity). In previous research (Koustelios, Theodorakis \& Goulimaris, 2004) the reliability was found to be adequate with Cronbach alpha coefficients for this instrument ranging from 0.85 for role ambiguity and 0.86 for role conflict. In Mukherjee and Malhotra's (2006) study conducted on 342 call centre employees, a Cronbach alpha coefficient of 0.85 was obtained. A simple principal components analysis was carried out on Role clarity items (as measured by the MRCAQ). An analysis of the Eigenvalues ( $>1.00$ ) and scree plot indicated that two factors could be extracted, which explained $44.95 \%$ of the total variance. Since this study is focusing on role clarity, only the items loading on this factor were utilised.

The Measuring Empowerment Questionnaire (MEQ) was developed by Spreitzer (1995) and is aimed at measuring the participants' psychological empowerment. The instrument consists of 12 items and is scored on a 7-point scale ranging from 'strongly disagree' (1) to 'strongly agree' (7). The measure has four sub-dimensions, namely (Spreitzer, 1995):

- meaning

- competence

- self-determination

- impact.

Typical items within these sub-dimensions are, for:

- Meaning: 'The work I do is meaningful to me.'

- Competence: 'I have mastered the skills necessary for my job.'

- Self-determination: 'I have significant autonomy in determining how to do my job.'

- Impact: 'I have a great deal of control over what happens in my department.'

A high score indicates high levels of empowerment. Regarding internal consistency, Stander and Rothmann (2009) reported the following alpha coefficients:

- Meaning: $\alpha=0.89$

- Competence: $\alpha=0.81$

- Self-determination: $\alpha=0.85$

- Impact: $\alpha=0.86$.

Stander and Rothmann (2009) found a 4-factor structure for the MEQ, which is in line with previous research (Spreitzer, 1995). Confirmatory factor analyses on MEQ which were conducted with AMOS for the purposes of this study showed that a 4-factor model of psychological empowerment (consisting of Meaning, Competence, Self-determination and Impact) fitted the data best $\left(\chi^{2} / d f=3.13\right.$; CFI $>0.90$; RMSEA < 0.08).

The Utrecht Work Engagement Scale (UWES) was developed by Schaufeli et al. (2002) and is aimed at measuring the participants' work engagement. The instrument consists of 17 items and is scored on a 7-point frequency scale, ranging from 'never' (0) to 'daily' (6). The measure has three scales, namely (Schaufeli et al., 2002):

- Vigour

- Dedication

- Absorption.

A typical item for Vigour is 'At my work I feel bursting with energy'. A typical item for Dedication is 'I am enthusiastic about my job'. A typical item for Absorption is 'I feel happy when I am working intensely'. A high score indicates 
high levels of engagement. The internal consistency of the measure ranges from a Cronbach alpha coefficient of 0.68 to 0.91 (Schaufeli et al., 2002). Cronbach alpha coefficients of 0.78 for Vigour, 0.89 for Dedication and 0.78 for Absorption were found by Storm and Rothman (2003). Research in various countries including South Africa showed that the fit of the hypothesised 3-factor structure to the data was superior to that of alternative factor models (Seppälä et al., 2008; Storm \& Rothmann, 2003). Confirmatory factor analyses on the UWES which were conducted with AMOS for the purposes of this study showed that a 3-factor model of work engagement (consisting of Vigour, Dedication and Absorption) fitted the data best $\left(\chi^{2} / d f=3.53\right.$; CFI > 0.90; RMSEA < 0.08).

The Intention to Leave Scale (ILS) was developed by Firth, Mellor, Moore and Loquet (2004) and is aimed at measuring the strength of participants' intentions to leave. The instrument consists of two items and is scored on a 5-point scale ranging from 'very often' (1) to 'rarely or never' (5). A typical item is 'How often do you think of leaving your present job?' (Firth et al., 2004, p. 187). A high score reflects a low intention to leave. Firth et al. (2004) found a Cronbach alpha coefficient of 0.75 , which is an adequate reliability score. The ILS consists of only two items and therefore a factor analysis investigating the loadings of items was not necessary.

\section{Research procedure}

An entire business unit $(N=240)$ in a chemical organisation was approached by means of a convenience sample. Permission was granted from the management team as well as the employees. Participation in this study was voluntary and all information was treated anonymously and with high regard to respondents' confidentiality. The raw data captured was converted by means of the SPSS program for further analyses.

\section{Statistical analysis}

In order to answer the research questions the SPSS programme (SPSS Inc, 2007) and AMOS program (Arbuckle, 2006) were used. Exploratory factor analysis was performed for this study to investigate the factor structure of the Leader Empowering Behaviour Questionnaire (LEBQ) and Measures of Role Clarity and Ambiguity Questionnaire (MRCAQ). Initially a principal components analysis was conducted on the constructs so that the Eigenvalues and scree plot could be investigated and so the number of factors could be extracted. Thereafter a principal axis factor analysis with a direct oblimin rotation was performed in order to determine factor loadings. Structural equation modelling, as implemented in AMOS (Arbuckle, 2006), was used to test the factorial models of the MEQ and the UWES, by using the maximum likelihood analyses. The following indexes produced by AMOS were used in this study: the Chi-square statistic $\left(\chi^{2}\right)$, which is the test of absolute fit of the model, the Comparative Fit Index (CFI) and the Root-Means-Square Error of Approximation (RMSEA).
Descriptive statistics were used to analyse the distribution of scores. Pearson correlation coefficients were used to determine the relationships between the variables. The statistical significance was set at $p<0.05$. Effect sizes were used to assess the practical significance of the correlation coefficients (Steyn, 2005). A cut-off point of 0.30 (medium effect) was set for practical significance of correlation coefficients (Cohen, 1988).

Canonical analyses were used to determine the relationships between sets of constructs (Tabachnick \& Fidell, 2001). Hierarchical multiple regression analyses were conducted with the variables in their continuous form. In the first step, the scales of the LEBQ were entered into the regression equation. In the second step the role ambiguity items of the MRCAQ were entered, whilst in the third step the scales of the MEQ were entered.

To investigate the moderating effects of role clarity, the predictors (i.e. leadership empowerment behaviour and psychological empowerment) and moderator (i.e. role clarity) were entered into a hierarchical multiple regression equation (with work engagement as dependent variable), followed by their interaction in the second step. The interaction term is represented by the product of two main effects (Aiken \& West, 1991). Also, in line with the procedure suggested by these authors, the independent variables and the moderator were centred before testing for the significance of the interaction term. To centre a variable, scores are put into deviation score form by subtracting the sample mean from all individuals' scores on the variable, thus producing a revised sample mean of zero.

\section{Results}

Descriptive statistics, Cronbach alpha coefficients and correlation coefficients for all of the constructs which were measured are illustrated in Table 2.

Table 2 shows that the Cronbach alpha coefficients for leader empowering behaviour, role clarity, psychological empowerment, engagement and intention to leave are all acceptable according to Foxcroft and Roodt (2005) who state that a Cronbach alpha coefficient of 0.65 or higher is acceptable.

Table 2 Shows that Development is positively related to Role clarity, Impact and Self-determination (practically significant, large effect). Development also correlated positively with Meaning, Vigour, Dedication, Absorption and Intention to Leave (practically significant, medium effect). Accountability correlated positively with Competence and Self-determination (practically significant, medium effect), whilst Authority is positively related to Selfdetermination (practically significant, large effect). Authority correlated positively with Role clarity, Meaning, Impact and Intention to Leave (practically significant, medium effect). Role clarity related positively to Competence, Impact, Selfdetermination, Vigour, Dedication and Intention to Leave 
(practically significant, medium effect). Role clarity also correlated with Meaning (practically significant, large effect). Meaning correlated positively with Vigour, Dedication and Absorption (practically significant, large effect). Meaning also related positively to Intention to Leave (practically significant, medium effect). Impact related positively with Dedication (practically significant, large effect); and with Vigour, Absorption and Intention to Leave (all practically significant, medium effect). Self-determination correlated positively with Vigour and Dedication (both practically significant, medium effect). Vigour and Absorption are positively related to Intention to Leave (practically significant, medium effect). Dedication relates positively with Intention to Leave (practically significant, large effect).

Next, a canonical analysis was done to analyse the relationship between two sets of variables namely the leader empowering behaviour, role clarity and psychological empowerment set with the work engagement and intention to leave set. The results are illustrated in Table 3 below.
The first statistically significant canonical correlation was $0.80[F(32,617.46)=7.60, p<0.0001]$. The second statically significant canonical correlation was 0.35 $[F(21,482.96)=1.71, p<0.02]$. The two sets of the first canonical variate shared $64 \%$ of the variance, whilst the two sets of the second canonical variate shared $12.25 \%$ of the variance.

With a cut-off correlation of 0.30 the variables in the Leader Empowering Behaviour, Role Clarity and Psychological Empowerment Set that were correlated with the first canonical variate were Development (-0.57), Authority (-0.38), Role Clarity (-0.59), Meaning (-0.88), Impact (-0.72) and Selfdetermination (-0.43). Amongst the Work Engagement and Intention to Leave set, Vigour (-0.79), Dedication (-0.98) and Absorption (-0.75) correlated with the first canonical variate. The variables in the Leader Empowering Behaviour, Role Clarity and Psychological Empowerment Set that correlated with the second canonical variate was Accountability (-0.50), Authority (-0.40), Role Clarity (0.32) and Competence (-0.45). Amongst the Work Engagement Set Vigour

TABLE 2: Descriptive statistics, Cronbach alpha coefficients and correlation coefficients of the measuring instruments.

\begin{tabular}{|c|c|c|c|c|c|c|c|c|c|c|c|c|c|c|}
\hline Item & Mean & SD & $\alpha$ & 1 & 2 & 3 & 4 & 5 & 6 & 7 & 8 & 9 & 10 & 11 \\
\hline 1. Development & 4.76 & 1.43 & 0.94 & - & - & - & - & - & - & - & - & - & - & - \\
\hline 2. Accountability & 5.68 & 1.15 & 0.81 & $0.41 * * \dagger$ & - & - & - & - & - & - & - & - & - & - \\
\hline 3. Authority & 4.94 & 1.45 & 0.90 & $0.77 * *$ & $0.41^{* * \dagger}$ & - & - & - & - & - & - & - & - & - \\
\hline 4. Role clarity & 5.13 & 1.04 & 0.76 & $0.51^{* *}+$ & $0.15^{*}$ & $0.36 * * \dagger$ & - & - & - & - & - & - & - & - \\
\hline 5. Competence & 6.11 & 0.91 & 0.77 & $0.22^{* *}$ & $0.30 * * \dagger$ & $0.19^{*}$ & $0.36 * * \dagger$ & - & - & - & - & - & - & - \\
\hline 6. Meaning & 5.72 & 1.12 & 0.89 & $0.36^{* * \dagger}$ & $0.17^{*}$ & $0.34 * * \dagger$ & $0.50 * *$ & $0.55 * *$ & - & - & - & - & - & - \\
\hline 7. Impact & 4.83 & 1.43 & 0.82 & $0.51 * *$ & $0.16^{*}$ & $0.49 * * \dagger$ & $0.43 * * \dagger$ & $0.25^{* *}$ & $0.58 * * !$ & - & - & - & - & - \\
\hline 8. Self-determination & 5.35 & 1.28 & 0.81 & $0.51 * * t$ & $0.36 * * \dagger$ & $0.58 * *$ & $0.41 * * \dagger$ & $0.36^{* * \dagger}$ & $0.44^{* * \dagger}$ & $0.60 * *$ & - & - & - & - \\
\hline 9. Vigour & 4.50 & 1.17 & 0.81 & $0.37^{* * \dagger}$ & $0.16^{*}$ & $0.29 * *$ & $0.32 * * \dagger$ & $0.27^{* *}$ & $0.62 * * \dagger$ & $0.46 * * \dagger$ & $0.33^{* * \dagger}$ & - & - & - \\
\hline 10. Dedication & 4.58 & 1.44 & 0.90 & $0.42^{* *} \dagger$ & 0.07 & $0.27^{* *}$ & $0.47^{* * \dagger}$ & $0.20 * *$ & $0.69 * * \dagger$ & $0.58 * *$ & $0.33^{* * \dagger}$ & $0.80 * *$ & - & - \\
\hline 11. Absorption & 4.30 & 1.22 & 0.79 & $0.34 * * \dagger$ & 0.12 & $0.23 * *$ & $0.24 * *$ & $0.16^{*}$ & $0.55^{* *} \dagger$ & $0.42 * * \dagger$ & $0.26 * *$ & $0.76 * *$ & $0.71 * *+$ & - \\
\hline 12. Intention to leave & 3.16 & 1.25 & 0.73 & $0.40 * * \dagger$ & 0.10 & $0.30 * * \dagger$ & $0.36 * * \dagger$ & $0.15^{*}$ & $0.49 * * \dagger$ & $0.34 * * \dagger$ & $0.27 * *$ & $0.46 * * \dagger$ & $0.53 * *+$ & $0.34 * * \dagger$ \\
\hline
\end{tabular}

ntion to leave

SD, standard deviation.

$\dagger$, Correlation is practically significant $r>0.30$ (medium effect).

\pm , Correlation is practically significant $r>0.50$ (large effect).

$*$, Statistically significant $p<0.05$

$* *$, Statistically significant $p<0.01$

TABLE 3: Canonical correlations between leader empowering behaviour, role clarity and psychological empowerment set and the work engagement and intention to leave set.

\begin{tabular}{|c|c|c|c|c|}
\hline \multirow[t]{2}{*}{ Canonical correlations } & \multicolumn{2}{|c|}{ First canonical variate } & \multicolumn{2}{|c|}{ Second canonical variate } \\
\hline & Correlation & Coefficient & Correlation & Coefficient \\
\hline \multicolumn{5}{|c|}{ Leader empowerment behaviour, role clarity and psychological empowerment set } \\
\hline Development & -0.57 & -0.20 & -0.23 & -0.20 \\
\hline Accountability & -0.10 & -0.20 & -0.50 & -0.20 \\
\hline Authority & -0.38 & -0.39 & -0.40 & -0.39 \\
\hline Role Clarity & -0.59 & 0.80 & 0.32 & 0.80 \\
\hline Competence & -0.24 & -0.34 & -0.45 & -0.34 \\
\hline Meaning & -0.88 & -0.53 & -0.29 & -0.53 \\
\hline Impact & -0.72 & 0.63 & 0.12 & 0.63 \\
\hline Self-determination & -0.43 & -0.22 & -0.28 & -0.22 \\
\hline Percent of variance & 0.30 & - & 0.12 & - \\
\hline Redundancy & 0.19 & - & 0.01 & - \\
\hline \multicolumn{5}{|c|}{ Work engagement and intention to leave set } \\
\hline Vigour & -0.79 & 0.09 & -0.50 & -1.35 \\
\hline Dedication & -0.98 & -0.81 & 0.08 & 1.57 \\
\hline Absorption & -0.75 & -0.16 & -0.35 & -0.33 \\
\hline Intention to leave & -0.68 & -0.24 & -0.23 & -0.34 \\
\hline Percent of variance & 0.41 & - & 0.01 & - \\
\hline Redundancy & 0.65 & - & 0.11 & - \\
\hline Canonical correlation & 0.80 & - & 0.35 & - \\
\hline
\end{tabular}


(-0.50) and Absorption (-0.35) correlated with the second canonical variate. Therefore leader empowering behaviour (Development, Accountability and Authority), Role Clarity and psychological empowerment (Competence, Meaning, Impact and Self-determination) are strongly related to the three categories of work engagement (Vigour, Dedication and Absorption) and Intention to Leave. Based on the above analysis hypothesis 1 is accepted.

Table 4 summarises the regression analysis with leader empowering behaviour (as measured by the LEBQ), role clarity (as measured by the MRCAQ) and psychological empowerment (as measured by the MEQ) as independent variables and Vigour, Dedication and Absorption (as measured by the UWES) as the dependent variables.

Leader empowering behaviour and work engagement: Firstly, multiple regression analyses with Vigour, Dedication and Absorption (as measured by the UWES) as dependent variables and the three dimensions of leader empowering behaviour (as measured by LEBQ) as independent variables showed statistically significant $F$-values for Vigour $\left[F(3,175)=9.24, p<0.0001, R^{2}=0.14\right]$, Dedication $\left[F(3,175)=14.04, p<0.0001, R^{2}=0.19\right]$ and Absorption $\left[F(3,175)=7.60, p<0.0001, R^{2}=0.12\right]$. Regarding Vigour, one variable, namely Development made a statistical significant contribution to the regression model $(\beta=0.35, t=3.18$, $p<0.01$ ). Development was also the only variable which made a statistical significant contribution to the regression model for Dedication $(\beta=0.54, t=5.06, p<0.01)$ and Absorption $(\beta=0.40, t=3.57, p<0.01)$.

Leader empowering behaviour, role clarity and work engagement: Secondly, multiple regression analyses with Vigour, Dedication and Absorption (as measured by the
UWES) as dependent variables and the three dimensions of leader empowering behaviour (as measured by LEBQ) and Role Clarity (as measured by the MRCAQ) as independent variables showed statistically significant $F$-values for Vigour $\left[F(4,174)=8.19, p=0.00, \Delta R^{2}=0.02\right]$, Dedication $\left[F(4,174)=16.29, p=0.00, \Delta R^{2}=0.08\right]$ and Absorption $\left[F(4,174)=5.95, p=0.00, \Delta R^{2}=0.01\right]$. Regarding Vigour, two variables, namely Development $(\beta=0.25, t=2.09$, $p<0.05)$ and Role Clarity $(\beta=0.17, t=2.12, p<0.05)$ made statistically significant contributions to the regression model. Development $(\beta=0.35, t=3.12, p<0.01)$ and Role Clarity $(\beta=0.33, t=4.33, p<0.01)$ made a statistically significant contributions to the regression model for Dedication. For Absorption, Development was also the only variable which made a statistical significant contribution to the regression model $(\beta=0.35, t=2.87, p<0.01)$.

Leader empowering behaviour, role clarity, psychological empowerment and work engagement: Thirdly, multiple regression analyses with Vigour, Dedication and Absorption (as measured by the UWES) as dependent variables and the three dimensions of leader empowering behaviour (as measured by LEBQ), Role Clarity (as measured by the MRCAQ) and the four dimensions of psychological empowerment (as measured by the MEQ) as independent variables showed statistically significant $F$-values for:

- $\operatorname{Vigour}\left[F(8,170)=13.17, p<0.0001, \Delta R^{2}=0.27\right]$

- Dedication $\left[F(8,170)=33.48, p<0.0001, \Delta R^{2}=0.34\right]$

- Absorption $\left[F(8,170)=13.15, p<0.0001, \Delta R^{2}=0.26\right]$.

Regarding Vigour, two variables, namely Development $(\beta=0.24, t=2.36, p<0.05)$ and Meaning $(\beta=0.61$, $t=7.16, p<0.01)$ made statistically significant contributions to the regression model. Development $(\beta=0.30, t=3.54$, $p<0.01)$, Authority $(\beta=-0.23, t=-2.90, p<0.01)$, Competence

TABLE 4: Multiple regression analyses with leader empowering behaviour, role clarity and psychological empowerment as independent variables and vigour, dedication and absorption as dependent variable.

\begin{tabular}{|c|c|c|c|c|c|c|c|c|c|c|c|c|c|c|c|}
\hline \multirow[t]{2}{*}{ Independent Variable } & \multicolumn{5}{|c|}{ Vigour } & \multicolumn{5}{|c|}{ Dedication } & \multicolumn{5}{|c|}{ Absorption } \\
\hline & $\boldsymbol{B}$ & SE & $p$ & $\boldsymbol{F}$ & $\Delta R^{2}$ & $\boldsymbol{B}$ & SE & $p$ & $\boldsymbol{F}$ & $\Delta R^{2}$ & $B$ & SE & $p$ & $\boldsymbol{F}$ & $\Delta R^{2}$ \\
\hline Step 1 & - & - & - & $9.24 *$ & $0.14^{*}$ & - & - & - & $14.04 *$ & $0.19 *$ & - & - & - & $7.60 *$ & $0.12 *$ \\
\hline (Constant) & 4.50 & 0.08 & 0.00 & - & - & 4.59 & 0.10 & 0.00 & - & - & 4.30 & 0.09 & 0.00 & - & - \\
\hline Development & 0.29 & 0.09 & $0.00^{*}$ & - & - & 0.54 & 0.11 & $0.00^{*}$ & - & - & 0.34 & 0.10 & $0.00 *$ & - & - \\
\hline Accountability & 0.01 & 0.08 & 0.86 & - & - & -0.14 & 0.10 & 0.15 & - & - & -0.03 & 0.08 & 0.76 & - & - \\
\hline Authority & 0.01 & 0.09 & 0.89 & - & - & -0.10 & 0.11 & 0.37 & - & - & -0.06 & 0.09 & 0.53 & - & - \\
\hline Step 2 & - & - & - & $8.19 *$ & $0.02 *$ & - & - & - & $16.29 *$ & $0.08^{*}$ & - & - & - & $5.95^{*}$ & $0.01 *$ \\
\hline (Constant) & 4.50 & 0.08 & 0.00 & - & - & 4.59 & 0.09 & $0.00 *$ & - & - & 4.30 & 0.09 & $0.00 *$ & - & - \\
\hline Development & 0.21 & 0.10 & $0.04 *$ & - & - & 0.35 & 0.11 & $0.00 *$ & - & - & 0.30 & 0.10 & $0.01 *$ & - & - \\
\hline Accountability & 0.03 & 0.08 & 0.75 & - & - & -0.11 & 0.09 & 0.23 & - & - & -0.02 & 0.08 & 0.81 & - & - \\
\hline Authority & 0.02 & 0.09 & 0.81 & - & - & -0.08 & 0.10 & 0.46 & - & - & -0.06 & 0.09 & 0.56 & - & - \\
\hline Role Clarity & 0.19 & 0.09 & $0.04 *$ & - & - & 0.45 & 0.11 & $0.00^{*}$ & - & - & 0.10 & 0.10 & 0.32 & - & - \\
\hline Step 3 & - & - & - & $16.06 *$ & $0.27 *$ & - & - & - & $33.48^{*}$ & $0.34 *$ & - & - & - & $13.15^{*}$ & $0.26 *$ \\
\hline (Constant) & 4.50 & 0.07 & 0.00 & - & - & 4.59 & 0.07 & 0.00 & - & - & 4.30 & 0.07 & 0.00 & - & - \\
\hline Accountability & 0.03 & 0.07 & 0.63 & - & - & -0.03 & 0.07 & 0.66 & - & - & 0.02 & 0.08 & 0.82 & - & - \\
\hline Authority & -0.09 & 0.08 & 0.26 & - & - & -0.23 & 0.08 & $0.00 *$ & - & - & -0.17 & 0.09 & $0.05^{*}$ & - & - \\
\hline Role Clarity & -0.09 & 0.09 & 0.28 & - & - & 0.12 & 0.09 & 0.15 & - & - & -0.17 & 0.09 & 0.07 & - & - \\
\hline Competence & -0.14 & 0.10 & 0.15 & - & - & -0.39 & 0.10 & $0.00 *$ & - & - & 0.26 & 0.10 & $0.01 *$ & - & - \\
\hline Meaning & 0.64 & 0.09 & $0.00 *$ & - & - & 0.83 & 0.09 & $0.00 *$ & - & - & 0.66 & 0.10 & $0.00 *$ & - & - \\
\hline Impact & 0.08 & 0.07 & 0.27 & - & - & 0.23 & 0.07 & $0.00 *$ & - & - & 0.10 & 0.08 & 0.19 & - & - \\
\hline Self-determination & 0.00 & 0.08 & 0.96 & - & - & -0.05 & 0.08 & 0.50 & - & - & -0.01 & 0.08 & 0.95 & - & - \\
\hline
\end{tabular}


$(\beta=-0.24, t=-4.03, p<0.01)$, Meaning $(\beta=0.64, t=9.08$, $p<0.01)$ and Impact $(\beta=0.23, t=3.32, p<0.01)$ made statistically significant contributions to the regression model for Dedication. For Absorption, Development $(\beta=0.33$, $t=3.10, p<0.01)$ Authority $(\beta=-0.17, t=-2.00, p<0.05)$, Competence $(\beta=0.26, t=-2.47, p<0.01)$ and Meaning ( $\beta=0.61, t=6.84 p<0.01)$ were the only variables which made statistically significant contributions to the regression model.

The multiple regression analysis shows that leader empowering behaviour, role clarity and psychological empowerment predicts a large percentage of the variance in engagement. More specifically, leader empowering behaviour, role clarity and psychological empowerment explains $43 \%$ of the variance in Vigour, $61 \%$ of the variance in Dedication and $38 \%$ of the variance in Absorption.

Based on the aforementioned statistical analysis hypothesis 2 is accepted. Leader empowering behaviour, role clarity and psychological empowerment predict work engagement within the business unit.

Moderation effects of role clarity: The moderation effects of role clarity on the relationship between leadership empowering behaviour as (measured by the LEBQ) and psychological empowerment (as measured by the MEQ) and Work Engagement (Dedication and Absorption) were tested with hierarchical regression procedures. In an attempt to test the possibility of interaction effects, the centred predictors and moderators were entered first into the regression equation followed by their interactions in the second step to predict facets of work engagement. The results of the hierarchical regressions are reported in Table 5.

Table 5 shows that the interaction terms amongst leader empowering behaviour, psychological empowerment and role clarity to predict Dedication and Absorption yielded statistically significant effects $\left[F_{\text {Dedication }}(15,163)=19.60\right.$, $\Delta R^{2}=0.03, p<0.05$ and $F_{\text {Absorption }}(15,163)=8.25, \Delta R^{2}=0.05$, $p<0.05]$. Although small, the significant interaction effects were plotted as indicated by Figures 2, 3 and 4 .

Figure 1 shows that at a high level of Role Clarity (compared with a low level); high Competence was associated with a lower level of Dedication. Figure 2 shows that at a high level of Role Clarity (compared with a low level), high Meaning had a stronger effect on Dedication. Figure 3 shows that at a low level of Role Clarity (compared with a high level); high Development had a stronger effect on Absorption. Therefore, hypothesis 2 is accepted. Role clarity moderates the relationship between leader empowering behaviour, psychological empowerment and work engagement within the business unit.

Finally, a regression analysis was computed to determine if engagement and its three sub-scales predict intention to leave. The results are reported in Table 6.

Table 6 summarises the regression analysis with work engagement as a predictor of Intention to Leave. The regression analysis produced a statistically significant model

TABLE 5: Interaction of leader empowering behaviour, psychological empowerment and role clarity on work engagement.

\begin{tabular}{|c|c|c|c|c|c|c|c|c|c|c|c|c|c|c|c|}
\hline \multirow[t]{2}{*}{ Independent Variable } & \multicolumn{5}{|c|}{ Vigour } & \multicolumn{5}{|c|}{ Dedication } & \multicolumn{5}{|c|}{ Absorption } \\
\hline & $B$ & SE & $p$ & $\boldsymbol{F}$ & $\Delta R^{2}$ & $B$ & SE & $p$ & $\boldsymbol{F}$ & $\Delta R^{2}$ & $B$ & SE & $p$ & $\boldsymbol{F}$ & $\Delta R^{2}$ \\
\hline Step 1 & - & - & - & $16.06 *$ & $0.27^{*}$ & - & - & - & $33.48 *$ & $0.34^{*}$ & - & - & - & $13.15^{*}$ & $0.26 *$ \\
\hline (Constant) & 4.50 & 0.07 & 0.00 & - & - & 4.59 & 0.07 & 0.00 & - & - & 4.30 & 0.07 & 0.00 & - & - \\
\hline Development & 0.20 & 0.08 & $0.02 *$ & - & - & 0.30 & 0.08 & $0.00 *$ & - & - & 0.28 & 0.09 & $0.00 *$ & - & - \\
\hline Accountability & 0.03 & 0.07 & 0.63 & - & - & -0.03 & 0.07 & 0.66 & - & - & 0.02 & 0.08 & 0.82 & - & - \\
\hline Authority & -0.09 & 0.08 & 0.26 & - & - & -0.23 & 0.08 & $0.00 *$ & - & - & -0.17 & 0.09 & $0.05^{*}$ & - & - \\
\hline Role clarity & -0.09 & 0.09 & 0.28 & - & - & 0.12 & 0.09 & 0.15 & - & - & -0.17 & 0.09 & 0.07 & - & - \\
\hline Competence & -0.14 & 0.10 & 0.15 & - & - & -0.39 & 0.10 & $0.00 *$ & - & - & 0.26 & 0.10 & $0.01 *$ & - & - \\
\hline Meaning & 0.64 & 0.09 & $0.00 *$ & - & - & 0.83 & 0.09 & $0.00 *$ & - & - & 0.66 & 0.10 & $0.00 *$ & - & - \\
\hline Impact & 0.08 & 0.07 & 0.27 & - & - & 0.23 & 0.07 & $0.00 *$ & - & - & 0.10 & 0.08 & 0.19 & - & - \\
\hline Self-determination & 0.00 & 0.08 & 0.96 & - & - & -0.05 & 0.08 & 0.50 & - & - & -0.01 & 0.08 & 0.95 & - & - \\
\hline Step 2 & - & - & - & $9.33^{*}$ & $0.03 *$ & - & - & - & $19.60^{*}$ & $0.03 *$ & - & - & - & $8.25^{*}$ & $0.05^{*}$ \\
\hline (Constant) & 4.48 & 0.08 & 0.00 & - & - & 4.63 & 0.08 & 0.00 & - & - & 4.37 & 0.09 & 0.00 & - & - \\
\hline Development & 0.15 & 0.09 & 0.09 & - & - & 0.23 & 0.09 & $0.01^{*}$ & - & - & 0.26 & 0.09 & $0.01^{*}$ & - & - \\
\hline Accountability & 0.06 & 0.07 & 0.38 & - & - & -0.03 & 0.07 & 0.72 & - & - & 0.08 & 0.08 & 0.29 & - & - \\
\hline Authority & -0.09 & 0.08 & 0.28 & - & - & -0.22 & 0.08 & $0.01^{*}$ & - & - & -0.21 & 0.09 & $0.02^{*}$ & - & - \\
\hline Role clarity & -0.05 & 0.09 & 0.59 & - & - & 0.13 & 0.09 & 0.13 & - & - & -0.15 & 0.09 & 0.11 & - & - \\
\hline Competence & -0.27 & 0.12 & $0.01^{*}$ & - & - & -0.49 & 0.11 & $0.00 *$ & - & - & -0.38 & 0.11 & $0.00^{*}$ & - & - \\
\hline Meaning & 0.70 & 0.10 & $0.00 *$ & - & - & 0.94 & 0.10 & $0.00 *$ & - & - & 0.75 & 0.10 & $0.00^{*}$ & - & - \\
\hline Impact & 0.11 & 0.07 & 0.13 & - & - & 0.22 & 0.07 & $0.00 *$ & - & - & 0.11 & 0.08 & 0.15 & - & - \\
\hline Self-determination & 0.01 & 0.08 & 0.87 & - & - & -0.05 & 0.08 & 0.50 & - & - & -0.01 & 0.09 & 0.94 & - & - \\
\hline Development $\times$ Role clarity & 0.00 & 0.08 & 0.96 & - & - & -0.07 & 0.08 & 0.41 & - & - & -0.18 & 0.09 & $0.04^{*}$ & - & - \\
\hline Accountability $\times$ Role clarity & -0.10 & 0.07 & 0.15 & - & - & 0.06 & 0.07 & 0.38 & - & - & -0.12 & 0.07 & 0.10 & - & - \\
\hline Authority $\times$ Role clarity & 0.01 & 0.08 & 0.95 & - & - & 0.00 & 0.08 & 0.97 & - & - & 0.09 & 0.09 & 0.29 & - & - \\
\hline Competence $\times$ Role clarity & -0.17 & 0.09 & 0.07 & - & - & -0.21 & 0.09 & $0.03 *$ & - & - & -0.10 & 0.10 & 0.31 & - & - \\
\hline Meaning $\times$ Role clarity & 0.11 & 0.08 & 0.18 & - & - & 0.20 & 0.08 & $0.02 *$ & - & - & 0.06 & 0.09 & 0.48 & - & - \\
\hline Impact $\times$ Role clarity & 0.05 & 0.07 & 0.52 & - & - & -0.05 & 0.07 & 0.53 & - & - & -0.06 & 0.08 & 0.43 & - & - \\
\hline Self determination $\times$ Role clarity & -0.01 & 0.08 & 0.94 & - & - & -0.02 & 0.08 & 0.76 & - & - & 0.14 & 0.09 & 0.11 & - & - \\
\hline
\end{tabular}

$\mathrm{SE}$, standard error.

$*, p<0.05$ 


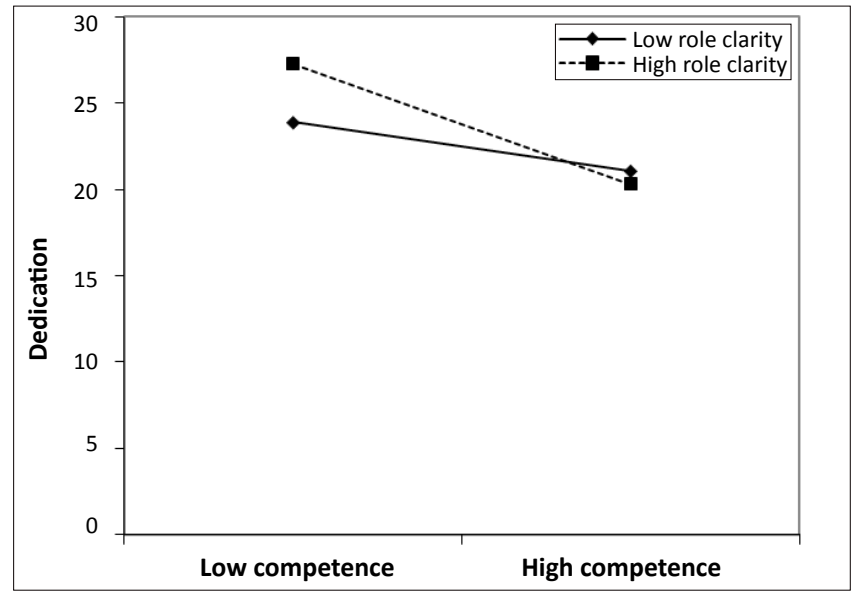

FIGURE 2: Interaction between competence and role clarity with dedication as dependent variable.

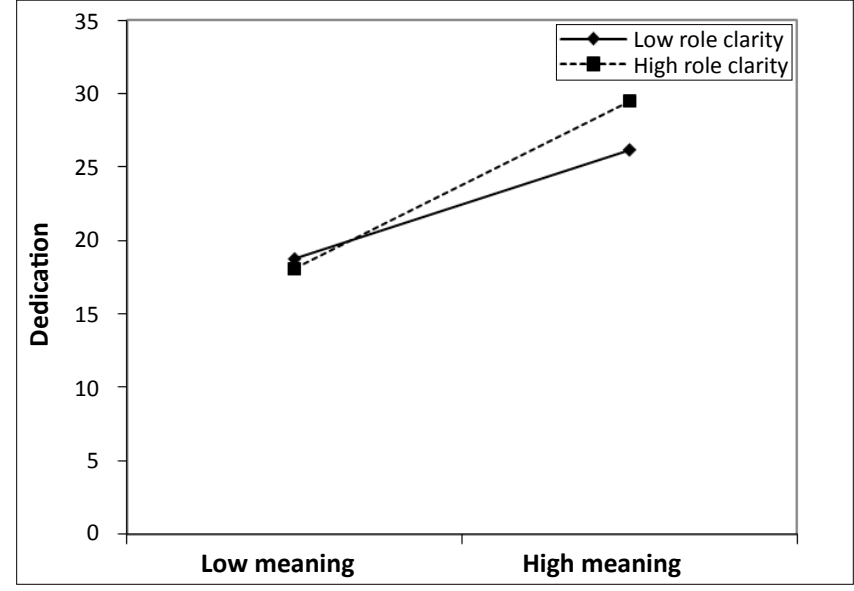

FIGURE 3: Interaction between meaning and role clarity with dedication as dependent variable.

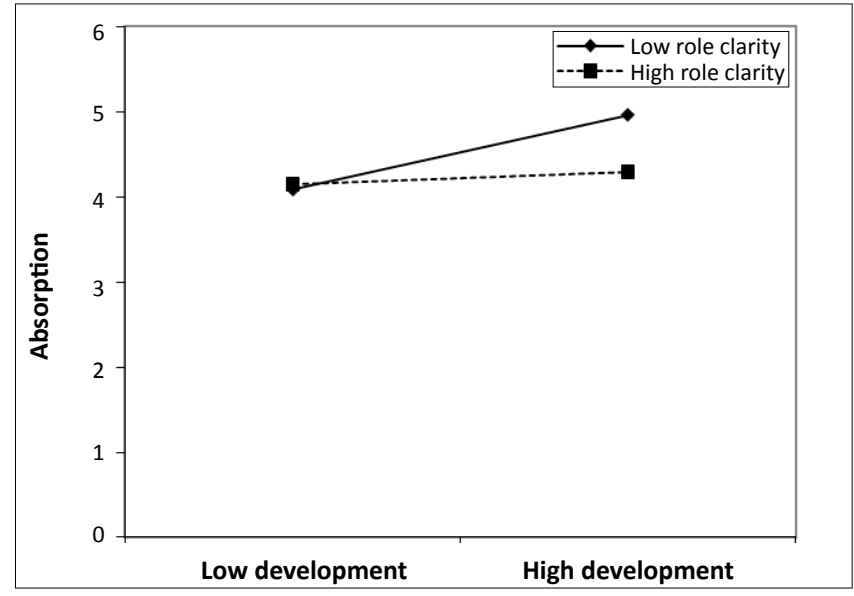

FIGURE 4: Interaction between development and role clarity with absorption as dependent variable.

$(F(3,175)=24.25 ; p=0.00)$, accounting for approximately $29 \%$ of the variance. More specifically, it seems that Dedication ( $\beta=0.43, t=4.51, p=0.00)$ predicts Intention to Leave. This result provides support for hypothesis 3 .

\section{Discussion}

The aim of this study was to determine firstly, whether leader empowering behaviour, role clarity and psychological empowerment predict employee engagement, secondly if role clarity moderates the relationship between leader empowering behaviour, psychological empowerment and work engagement and finally to determine if work engagement predicts intention to leave within the business unit.

The analyses showed that a leader's behaviour is related to employees' experiences of the work environment. A higher level of development was related to higher role clarity. Therefore, when a leader focuses on the development of employee, they are more aware of the expectations that are placed upon them. Higher levels of development relate to higher levels of impact; therefore, an empowering leader ensures that employees feel they can influence their work (Nielsen et al., 2008). Furthermore, higher levels of authority correlated with higher levels of self-determination, indicating that when a leader delegates authority appropriately, employees will experience autonomy in determining how to fulfil the expectations placed upon them. It is clear that leader empowering behaviour has a strong relationship with role clarity and psychological empowerment.

High levels of meaning correlated with high levels of vigour, dedication and absorption. Therefore, when employees experience their work as meaningful they will concurrently experience higher levels of energy in doing their work, be more enthusiastic in completing work-related tasks and demonstrate high levels of focus in their work. High levels of impact are related to elevated levels of dedication, which indicates that when employees feel they have control over their work environment they will react with increased eagerness in doing their work. This is supported in the findings of Stander and Rothmann (2010).

When employees experience high levels of dedication they will be less likely to have intentions of leaving. Employees who are enthusiastic about their work are more likely to have positive emotions about their work environment and as a result will be less likely to think about leaving their organisation. Hence, the more engaged an employee is the less likely he or she will be to have cognitions of leaving (see Simpson, 2009).

The canonical analysis showed that leader empowering behaviour (development, accountability and authority), role clarity and psychological empowerment (competence, meaning, impact and self-determination) are strongly related to the three categories of work engagement (vigour, dedication and absorption) and intention to leave.

The results of the multiple regression analysis showed that vigour was predicted by development, role clarity and meaning. Therefore, when leaders provide employees with

TABLE 6: Regression analysis with intention to leave as dependent variable.

\begin{tabular}{lllllll}
\hline Independent variable & & $\boldsymbol{B}$ & $\mathrm{SE}$ & $\boldsymbol{p}$ & $\boldsymbol{F}$ & $\boldsymbol{R}^{2}$ \\
\hline 1 & (Constant) & 0.98 & 0.33 & 0.00 & $24.25^{*}$ & 0.29 \\
& Vigour & 0.18 & 0.13 & 0.15 & - & - \\
& Dedication & 0.43 & 0.10 & $0.00^{*}$ & - & - \\
& Absorption & -0.14 & 0.11 & 0.18 & - & - \\
\hline
\end{tabular}

$\mathrm{SE}$, standard error

$*, p<0.05$ 
frequent opportunities to develop their skills and ensure that expectations are clearly stated and when employees experience their work as meaningful, they will respond with positive affective responses like physical strength, emotional energy and cognitive liveliness. Rothmann and Jordaan (2006) found similar results in their study within a higher education institution.

Dedication, according to the multiple regression analysis, was predicted by development, role clarity, authority, competence, meaning and impact. This implies that when a leader is perceived as supportive, when information is shared and when authority is appropriately delegated, employees will derive a sense of significance from their work. Furthermore, when employees feel competent in their work, experience this work as meaningful and feel they have the ability to influence their work environment, the result will be employees who feel proud, enthusiastic and inspired. These findings are corroborated in previous research (Greco et al., 2006).

The multiple regression analysis also showed that absorption was predicted by development, authority, competence and meaning. Employees who are totally immersed in their work are led by managers who make development a priority and share their authority (Quesada, González \& Kent, 2008). Employees who believe in their capabilities and who experience alignment of their work roles, beliefs, values and behaviours are more likely to be immersed in their work.

With reference to the interaction effects, the following was found. Firstly, role clarity interacted with competence to affect employees' dedication. When role clarity is high, employees with a low competence experience higher levels of dedication. In other words, employees who experienced a low level of competence were more dedicated when role clarity was high. So role clarity is less of an issue for employees who feel competent, especially as far as their dedication is concerned.

Secondly, role clarity interacted with meaning to affect employees' dedication. Employees who experienced a high level of meaning were more dedicated when they experienced high role clarity. Finally, role clarity interacted with the developing of employees (as a facet of leader empowering behaviour) to affect absorption. Employees who experienced low role clarity were more absorbed in their work when they experienced that their leaders developed them.

Lastly, a regression analysis showed that dedication (a subconstruct of engagement) predicts an employee's intention to leave. Therefore, when employees feel inspired by their work and experience their work as challenging they will be less likely to have thoughts of leaving the organisation or their current position (Karlowicz \& Ternus, 2007).

In conclusion, the research found statistically significant relationships between leader empowering behaviour, role clarity, psychological empowerment, work engagement and intention to leave. It was also evident that development and meaningful work plays an extremely important role in the retention of talent. The retention of talent is a vital element in creating a positive organisation (Davenport \& Harris, 2007; Ulrich et al., 2008). This research is beneficial in highlighting the importance of employee development and empowerment in creating a positive organisation and, consequently, ensuring the retention of talent.

Based on the results various recommendations can be made. Organisations that want to be market leaders need to recognise the importance of focusing on overall wellness for both the organisation and its employees. The interest in applying positive psychology principles to the workplace is proving to be extremely beneficial, resulting in lower absenteeism, lower turnover, decreased stress levels and diminished alcohol and tobacco usage (Wilson et al., 2004). It is recommended that interventions focusing on the aspects promoting overall wellness be implemented in the business unit. Therefore, it is essential that the business unit understand the elements encompassed by a healthy organisation.

If the business unit wishes to benefit in terms of building a positive organisation and, consequently, talent retention, it should adopt empowerment behaviour in its management style. According to Nedd (2006), a leader has the strongest impact on an employee's intention to stay. Therefore the importance of leader behaviour in talent retention is vital. Development was found to be one of the most important aspects of leader empowering behaviour relating to retention (i.e. lower intentions of leaving). This is substantiated in previous research that found professional development to be the most important aspect leading to the retention of employees (Loeb \& Darling-Hammond, 2005; Rosser \& Townsend, 2006). Taplin and Winterton (2007) found that a proactive approach to avoiding the costs involved in employee turnover is best and that serious investment in training may be the answer for many organisations. Stander and Rothmann (2009) reiterate this by identifying the development of employees as a key competence for managers. They point out that in order to be a good people developer, managers should be coached and developed to delegate authority, hold employees accountable for outcomes, lead by example, encourage subordinates, show concern for others' feelings, allow participative decisionmaking, share information and coach and mentor people. It is therefore advisable that the business unit apply leader empowering behaviour practically. The following can act as a guide:

- Delegation of authority: leaders within the business unit must create an environment that encourages employees to be involved in decision-making.

- Accountability: it is the leaders' responsibility to ensure that all employees within the business unit are held accountable for the work they are assigned to, for performance and results and for customer satisfaction.

- Self-directed decision-making: leaders within the business unit must allow the employees to utilise their skills in formulating solutions independently, thereby allowing them to make decisions that affect their work.

- Information sharing: employees within the business unit must be given all the necessary information by the leader so that they are able to ensure high quality work performance within their assigned roles. 
- Skill development: leaders must make continuous learning, skills development and employee problemsolving a priority within the business unit.

It is also important to ensure that the employees' roles are clarified through the provision of the necessary information regarding expectations placed upon them. The extent to which information is successfully received and understood is also important. Tasks must be communicated to employees in such a way that their fit and function within the organisation is comprehensively understood. Leaders must ensure that employees have clear career paths, detailed job models and a structured process to consult when clarification of expectations is needed.

Interventions employed within the business unit should also take engagement into account as engagement contributes to the enhancement of work-life and promotes the well-being of employees (Bakker \& Demerouti, 2008). Through the utilisation of engagement, employees will become happier in their work environment and be less likely to think of leaving. Wildermuth and Pauken (2008) state that the first step that leaders need to take in engaging employees is to ensure that they themselves are engaged. Adopting this approach will ensure that employees are enthusiastic, energetic and focused on their work, which will essentially contribute to organisational success. Engaged employees promise higher productivity, improved customer satisfaction, increased profits and good safety records (Saks, 2006). The role of meaningful work is extremely important with regard to engagement efforts. The business unit should conduct stayin interviews, group discussions and meetings in order to establish whether employees experience their work as meaningful. Interventions can also focus on increasing the meaningfulness of work in order to increase the engagement of employees within the business unit (Dychtwald \& Morison, 2006).

The following limitations have been noted in terms of this study. The research design was cross-sectional and this limits the determination of cause-and-effect relationships; also, the participants' opinions, attitudes and feelings are representative at only one point in time. The sampling technique involved targeting an entire business unit. Although a larger sample would have been more beneficial, the sample size of 179 is a reasonable and representative sample size. The measures that were administered were in English and this may have been a limitation in the way in which items were understood by participants who were not English-speaking. Furthermore, these measures were selfreport measures and this may lead to 'method variance'.

Longitudinal studies should be employed to establish the causal relationships amongst the variables. To enhance external validity, the sample size of 179 should be expanded, both to reach a larger sample size as well as to obtain the involvement of more organisations. It would be beneficial to investigate the effect of leader empowering behaviour, role clarity, psychological empowerment and work engagement on absenteeism, general health and employee wellness (e.g. alcohol and substance abuse and stress).

\section{References}

Addae, H.M., Parboteeah, K.P., \& Velinor, N. (2008). Role stressors and organisationa commitment: public sector employment in St Lucia. International Journal of Manpower, 29, 567-582. doi:10.1108/01437720810904220

Aiken, L.S., \& West, S.G. (1991). Multiple regression: Testing and interpreting interactions. Newbury Park: Sage.

Arbuckle, J.L. (2006). AMOS user's guide version 7.0. Chicago: AMOS Development Corporation.

Arnold, J.A., Arad, S., Rhoades, J.A., \& Drasgow, F. (2000). The empowering leadership questionnaire: The construction and validation of a new scale for measuring leaders' behaviours. Journal of Organizational Behaviour, 21, 249-269. doi:10.1002/(SICI)1099-1379(200005)21:3<249::AID-JOB10>3.0.CO;2-\#

Avey, J.B., Hughes, L.W., Norman, S.M., \& Luthans, K. W. (2008). Using positivity, transformational leadership and empowerment to combat employee negativity. Leadership and Organisation Development Journal, 29, 110-126. doi:10.1108/01437730810852470

Bakker, A.B., \& Demerouti, E. (2008). Towards a model of work engagement. Career Development International, 13, 209-223. doi:10.1108/13620430810870476

Bakker, A.B., \& Schaufeli, W.B. (2008). Positive organisational behaviour: Engaged employees in flourishing organisations. Journal of Organizational Behaviour, 29, 147-154. doi:10.1002/job.515

Baskin, B. (2007, November). Vigor, dedication, and absorption: Work engagement among secondary English teachers in Indonesia. Paper presented at the annual AARE Conference, Fremantle, Perth.

Beehr, T.A., Glazer, S., Fischer, R. Linton, L.L., \& Hansen, C.P. (2009). Antecedents for achievement of alignment in organizations. Journal of Occupational and Organizational Psychology, 82, 1-20. doi:10.1348/096317908X310247

Bergiel, E.B., Nguyen, V.Q., Clenney, B.F., \& Taylor, G.S. (2009). Human resources practices, job embeddedness and intention to quit. Management Research News, 32, 205-219. doi:10.1108/01409170910943084

Bhatnagar, J. (2007). Talent management strategy of employee engagement in Indian ITES employees: key to retention. Employee Relations, 29, 640-663. doi:10.1108/01425450710826122

Boninelli, I. \& Meyer, T.N.A. (2004). Building human capital: South African perspectives. Cape Town: Knowres.

Bray, S.R., \& Brawley, L.R. (2002). Role efficacy, role clarity, and role performance effectiveness. Small Group Research, 33, 233-253. doi:10.1177/104649640203300204

Bryan, L.L., \& Joyce, C.I. (2007). Mobilizing minds: Creating wealth from talent in the 21st century organization. New York: McGraw Hill.

Burke, R.J., \& Cooper, C.L. (2009). The peak performing organization. New York: Routledge.

Cameron, K.S., Dutton, J.E. \& Quinn, R.E. (2003). Positive organisational scholarship: Meet the movement. Journal of Management Inquiry, 12, 266-271. doi:10.1177/1056492603256341

Carson, C.M., \& King, J.E. Jr. (2005). Leaving leadership: Solving leadership problems through empowerment. Management Decision, 43, 1049-1053. doi:10.1108/00251740510610044

Chen, J.C., \& Silverthorne, C. (2005). Leadership effectiveness, leadership style and employee readiness. Leadership and Organisation Development Journal, 26 , 280-288. doi:10.1108/01437730510600652

Coffman, C. (2002). Building a highly engaged workforce: How great managers inspire virtuous performance. Retrieved July 30, 2007, from http://www.gmj. gallup.com/content/238/Building-a-Highly-Engaged-Workforce.html

Cohen, J. (1988). Statistical power analysis for the behavioural sciences (2nd edn.) Hillsdale: Lawrence Erlbaum and Associates.

Conger, J.A., \& Kanungo, R.N. (1988). The empowerment process: Integrating theory and practice. Academic Management Review, 13, 471-482. doi:10.2307/258093

Conley, C. (2007). Peak: How great companies get their mojo from Maslow. San Francisco: Jossey-Bass.

Davenport, T.H. \& Harris, J.G. (2007). Competing on analytics. Boston: Harvard Business School Press.

Devi, V.R. (2009). Employee engagement is a two way street. Human Resource Management International Digest, 17, 3-4. doi:10.1108/09670730910940186

Dvir, T., Eden, D., Avolio, B.J., \& Shamir, B. (2002). Impact of transformational leadership on follower development and performance: A field experiment. Academy of Management Journal, 45, 735-44. doi:10.2307/3069307

Dwyer, T.C. (2001). Employee empowerment within a manufacturing environment Unpublished master's dissertation, North-West University, Vanderbijlpark, South Africa.

Dychtwald, K., \& Morison, R. (2006). Workforce crisis: How to beat the coming shortage of skills and talent. Boston: Harvard Business Press.

Firth, L., Mellor, D.J., Moore, A., \& Loquet, C. (2004). How can managers reduce employee intention to quit? Journal of Managerial Psychology, 19, 170-187. doi:10.1108/02683940410526127

Foxcroft, C., \& Roodt, G. (2005). An introduction to psychological assessment in the South African context ( 2 nd edn.). Cape Town: Oxford University Press.

Greasley, K., Bryman, A., Dainty, A., Price, A., Naismith, N., \& Soetanto, R. (2008) Understanding empowerment from an employee perspective. Team Performance Management, 14, 39-55. doi:10.1108/13527590810860195

Greco, P., Laschinger, H.K.S., \& Wong, C. (2006). Leader empowering behaviours, staff nurse empowerment and work engagement/burnout. Nursing Leadership, 19 nurse
$41-56$. 
Grobler, P., Wärnich, S., Carrell, M.R., Elbert, N.F., \& Hatfield, R.D. (2006). Human resource management in South Africa (3rd edn.). Cape Town: Thompson.

Harter, J.L., Schmidt, F.L., \& Hayes, T.L. (2002). Business unit-level relationship between employee satisfaction, employee engagement, and business outcomes: a meta-analysis. Journal of Applied Psychology, 87, 268-279. doi:10.1037/00219010.87.2.268, PMid:12002955

Hong, P., Nahm, A.Y. \& Doll, W.J. (2004). The role of project target clarity in an uncertain environment. International Journal of Operations and Production Management, 24, 1269-1291. doi:10.1108/01443570410569047

Kahumuza, J., \& Schlechter, A.F. (2008). Examining the direct and some mediated relationships between perceived support and intention to quit. Management Dynamics, 17, 2-19.

Karlowicz, K.A., \& Ternus, M.P. (2007). Issues influencing psychiatric nurse retention during the first year of employment: a case analysis. Journal of Nursing Management, 17, 49-58. doi:10.1111/j.1365-2834.2008.00850.x, PMid:19166522

Kaye, B., \& Jordan-Evans, S. (2000). Retention: tag, you're it! Training and Development: 29-34, April.

Klidas, A., van den Berg, P.T., \& Wilderom, C.P.M. (2006). Managing employee empowerment in luxury hotels in Europe. International Journal of Service Industry Management, 18, 70-88. doi:10.1108/09564230710732902

Konczak, L.J., Stelly, D.J., \& Trusty, M.L. (2000). Defining and measuring empowerment leader behaviours: development of an upward feedback instrument. Educational and Psychological Measurement, 60, 301-313. doi:10.1177/00131640021970420

Konrad, A.M. (2006). Engaging employees through high-involvement work practices. Ivey Business Journal, 1-6.

Koustelios, A., Theodorakis, N., \& Goulimaris, D. (2004). Role ambiguity, role conflict and job satisfaction among physical education teachers in Greece. Journal of Educational Management, 18, 87-92.

Kreisman, J.B. (2002). Insight into employee motivation, commitment and retention. Business Training Experts: Leadership Journal, 1-24.

Loeb, S., \& Darling-Hammond, L. (2005). How teaching conditions predict teache turnover in California schools. Peabody Journal of Education, 80, 44-70. doi:10.1207/s15327930pje8003_4

Luthans, F. (2002). Theneedforand meaning of positive organisational behaviour.Journal of Organisational Behaviour, 23, 695-706. doi:10.1108/02621710210426864

Luthans, F., \& Peterson, S.J. (2001). Employee engagement and manager selfefficacy: implications for managerial effectiveness and development. Journal of Management Development, 21, 376-387.

Macky, K., \& Boxall, P. (2008). High-involvement work processes, work intensification and employee well-being: a study of New Zealand worker experiences. Asia Pacific Journal of Human Resources, 46, 38-55. doi:10.1177/1038411107086542

Malone, T.W. (2004). The future work: How the new order of business will shape you organization, your management skills and your life. Boston: Harvard Business School Press.

Mardanov, I.S., Heischmidt, K., \& Henson, A. (2008). Leader-member exchange and job satisfaction bond and predicted employee turnover. Journal of Leadership and Organisational Studies, 15(2), 159-175. doi:10.1177/1548051808320985

Maré, Z. (2007). Leader empowering behaviour, organisational commitment and turnover intention, within the gold mining industry. Unpublished master's dissertation, North-West University, Potchefstroom, South-Africa.

Marquardt, M. (2002). Building the learning organisation: Mastering the five elements for corporate learning (2nd edn.). San Francisco: Davies-Black Publishing.

May, D.R., \& Harter, L.M. (2004). The psychological conditions of meaningfulness, safety and availability and the engagement of the human spirit at work. Journal of Occupational and Organisational Psychology, 77, 11-37. doi:10.1348/096317904322915892

McHugh, M. (2001). Employee absence: An impediment to organisational health in local government. The International Journal of Public Sector Management, 14 43-58. doi:10.1108/09513550110387066

Menon, S.T. (2001). Employee empowerment: An integrative psychological approach Applied Psychology: An International Review, 50, 153-180. doi:10.1111/1464 0597.00052

Mukherjee, A., \& Malhotra, N. (2006). Does role clarity explain employee-perceived service quality? International Journal of Service Industry Management, 17, 444-473. doi:10.1108/09564230610689777

Nedd, N. (2006). Perceptions of empowerment and intention to stay. Nursing Economics, 24, 489-497.

Nielsen, K., Randall, R. Yarker, J., \& Brenner, S. (2008). The effects of transformational leadership on followers' perceived work characteristics and psychological well-being: A longitudinal study. Work and Stress, 22, 16-32. doi:10.1080/02678370801979430

Park, J.S., \& Kim, T.H. (2009). Do types of organisational culture matter in nurse job satisfaction and turnover intention. Leadership in Health Services, 22, 20-38.

Prieto, L.L., Salanova, M.S., Martinez, I., \& Schaufeli, W. (2008). Extension of the job demands-resources model in the prediction of burnout and engagement among teachers over time. Psicothema, 20, 354-360.

Quesada, G., González, M.E., \& Kent, T. (2008). A road for achieving an international measure and understanding on leaders' behaviours. Leadership and Organization Development Journal, 29, 678-692. doi:10.1108/01437730810916631

Reynders, E. (2005). Job insecurity, psychological empowerment and work engagemen in a government organisation. Unpublished master's dissertation, North-West University, Vanderbijlpark, South Africa.

Rizzo, J.R., House, R.J., \& Lirtzman, S.I. (1970). Role conflict and ambiguity in complex organisations. Administrative Science Quarterly, 15, 150-163. doi: $10.2307 / 2391486$
Rosser, V.J., \& Townsend, B.K. (2006). Determining public 2-year college faculty's intent to leave: An empirical model. Journal of Higher Education, 77, 124-147. doi:10.1353/jhe.2006.0006

Rothmann, S., \& Jordaan, G.M.E. (2006). Job demands, job resources and work engagement of academic staff in South African higher education institutions. South African Journal of Industrial Psychology, 32(4), 87-96.

Russel, J.E.A. (2008). Promoting subjective well-being at work. Journal of Career Assessment, 16, 117-131. doi:10.1177/1069072707308142

Saks, A.M. (2006). Antecedents and consequences of employee engagement. Journa of Managerial Psychology, 21, 600-619. doi:10.1108/02683940610690169

Sauer, D. (2003). Psychological empowerment, leadership empowerment and job insecurity within a steel-manufacturing environment. Unpublished master's dissertation, North-West University, Vanderbijlpark, South Africa.

Schaufeli, W.B., Salanova, M., González-Romá, V., \& Bakker, A.B. (2002). The measurement of engagement and burnout: A two-sample confirmatory measurement of engagement and burnout: A two-sample confirmatory
factor analytic approach. Journal of Happiness Studies, $3,71-92$. factor analytic approach.
doi:10.1023/A:1015630930326

Sellgren, S., Ekvall, G., \&Tomson, G.2007. Nursingstaffturnover:Doesleadershipmatter? Leadership in Health Services, 20, 169-183. doi:10.1108/17511870710764023, PMid:20690462

Seppälä, P., Mauno, S., Feldt, T., Hakanen, J., Kinnunen, U. Tolvanen, A., \& Schaufeli, W.B. (2008). The construct validity of the Utrecht Work Engagement Scale: Multisample and longitudinal evidence. Journal of Happiness Studies, 10, 459-481. doi:10.1007/s10902-008-9100-y

Shaughnessy, J.J., \& Zechmeister, E.B. (1997). Research methods in psychology (4th edn.). New York: McGraw Hill

Simpson, M.R. (2009). Predictors of work engagement among medicalsurgical registered nurses. Western Journal Nursing Research, 31, 44-65. doi:10.1177/0193945908319993, PMid:18612088

Slatten, T. (2008). Antecedents and effects of emotional satisfaction on employee-perceived service quality. Managing Service Quality, 18, 370-386. doi:10.1108/09604520810885617

Snyder, C.R., \& Lopez, S.J. (2002). Handbook of positive psychology. New York: Oxford University Press.

Spreitzer, M.G. (1995). Psychological empowerment in the workplace: Dimensions, measurement and validation. Academy of Management Journal, 38, 1442-1465. doi:10.2307/256865

SPSS Inc. (2007). SPSS 16.0 for Windows. Chicago: Author.

Stander, M.W., \& Rothmann, S. (2009). Psychological empowerment of employees in selected organisations in South Africa. South African Journal of Industria Psychology, 35(1), 1-8.

Stander, M.W. \& Rothmann, S. (2010). Psychological empowerment, job insecurity, and employee engagement. SA Journal of Industrial Psychology, 36(1), 1-8. DOI:10.4102/ sajip.v36i1.849.

Steele, J.P., \& Fullagar, C.J. (2009). Facilitators and outcomes of student engagement in a college setting. The Journal of Psychology, 143, 5-27. doi:10.3200/JRLP.143.1.5-27, PMid:19157070

Steyn, H.S. (2005). Handleiding vir bepaling van effekgroottes-indekse en praktiese betekenisvolheid [Manual for determining effect size indices and practical significance]. Potchefstroom: Statistiese Konsultasiediens, Noordwes Universiteit.

Storm, K., \& Rothmann, S. (2003). A psychometric analysis of the Utrecht Work Engagement Scale in the South African police service. SA Journal of Industrial Psychology, 29, 62-70.

Tabachnick, K.W., \& Velthouse, B.A. (2001). Using multivariate statistics (4th edn.). Boston: Allyn and Bacon.

Taplin, I.M., \& Winterton, J. (2007). The importance of management style in labour retention. International Journal of Sociology and Social Policy, 27, 5-18. doi:10.1108/01443330710722724

Teh. P., Ooi, K., \& Yong, C. (2008). Does TQM impact on role stressors? A conceptual model. Industrial Management and Data Systems, 108, 1029-1044. doi:10.1108/02635570810904596

Thomas, K.W., \& Velthouse, B.A. (1990). Cognitive elements of empowerment: An "interpretive" model on intrinsic task motivation. Academy of Management Review, 15, 666-681. doi:10.2307/258687

Tjeku, M.S. (2006). Empowerment and job insecurity in a steel manufacturing organisation. Unpublished master's dissertation, North-West University, Vanderbijlpark, South Africa.

Townsend. P., \& Gebhardt. J. (2008). Employee engagement completely. Human Resource Management International Digest, 16, 22-24. doi:10.1108/09670730810869529

Ulrich, D., Brockbank, W., Johnson, D., Sandholtz, K., \& Younger, J. (2008). HR competencies: Mastery at the intrasection of people and business. Alexandria: Society for the Human Resource Management.

Weisberg, J. (1994). Measuring workers' burnout and intention to leave. Internationa Journal of Manpower, 15, 4-14. doi:10.1108/01437729410053590

Wildermuth, C.M.S., \& Pauken, P.D. (2008). A perfect match: decoding employee engagement: Part 1: Engaging cultures and leaders. Industrial and Commercial Training, 40(3), 122-128. doi:10.1108/00197850810868603

Wilson, M.G., DeJoy, D.M., Vandenberg, R.J., Richardson, H.A., \& McGrath, A.L. (2004). Work characteristics and employee health and well-being: Test of a model of healthy work organisation. Journal of Occupational and Organisational Psychology, 77, 565-588. doi:10.1348/0963179042596522 